\title{
Strengthening of Flat Slabs Against Punching Shear Using Post-Installed Shear Reinforcement
}

\author{
by Miguel Fernández Ruiz, Aurelio Muttoni, and Jakob Kunz
}

\begin{abstract}
A significant number of existing flat slabs currently require strengthening against punching shear for safety reasons (the increase of applied loads and deficiencies during design or construction) or to comply with more stringent code requirements. Available strengthening methods are, however, not completely satisfactory, or they cannot be applied in many cases (depending on the possibilities to enlarge column sizes or to intervene on the upper face of slabs). In this paper, an innovative system overcoming most of the previous difficulties is presented. It consists of inclined shear reinforcement installed within existing slabs by drilling holes only from the soffit of the slab and by bonding it with high-performance epoxy adhesive. The results of a test program on 12 full-size slabs $3.0 \times 3.0 \times 0.25 \mathrm{~m}(118 \times 118 \times 9.8 \mathrm{in}$.) show that such reinforcement is an efficient way to increase both the strength and deformation capacity of flat slabs. Finally, the design of the reinforcement based on the critical shear-crack theory (CSCT) is presented.
\end{abstract}

Keywords: bonded reinforcement; crack width; critical shear crack theory; post-installed reinforcement; punching shear strength; strengthening.

\section{INTRODUCTION}

The collapse of flat slabs without transverse reinforcement by punching shear has shown the danger of this failure mode. ${ }^{1,2}$ Punching develops in the slab around the column in a very brittle way and is followed by a sudden drop in the load-carrying capacity of the slab. This behavior leads to limited warning signs, increases the sensitivity of these structures to imposed deformations, allows very limited redistribution of internal forces, and propagates through the slab, eventually leading to the total collapse of the structure. ${ }^{1}$

A tragic example of this occurred recently in Switzerland ${ }^{1}$ on November 27, 2004, when a fire started inside a parking garage in Gretzenbach (refer to Fig. 1). After 90 minutes of fire, the slab punched around one column and immediately propagated to the others, leading to the collapse of the structure and to the death of seven firemen working inside. This tragedy was due to a series of factors, ${ }^{3}$ not only the fire (which in fact was not very significant), but also overloading of the structure (larger ground cover than expected), toocoarse approaches on the check of the punching shear strength (some of them in agreement to the codes applied at the time the garage was designed), and deficiencies in the construction. In addition, the thickness of the slab, large reinforcement ratio, and the fact that the slab did not have transverse reinforcement severely limited the deformation capacity of the structure. As a consequence, once the slab punched around one column, the progressive and sudden collapse of the structure could not be avoided.

Accidents like that of Gretzenbach have raised the question on the safety of existing flat slabs and, in many cases, how they should be strengthened against punching shear. ${ }^{1,3}$ Some typical solutions to strengthen against punching shear are
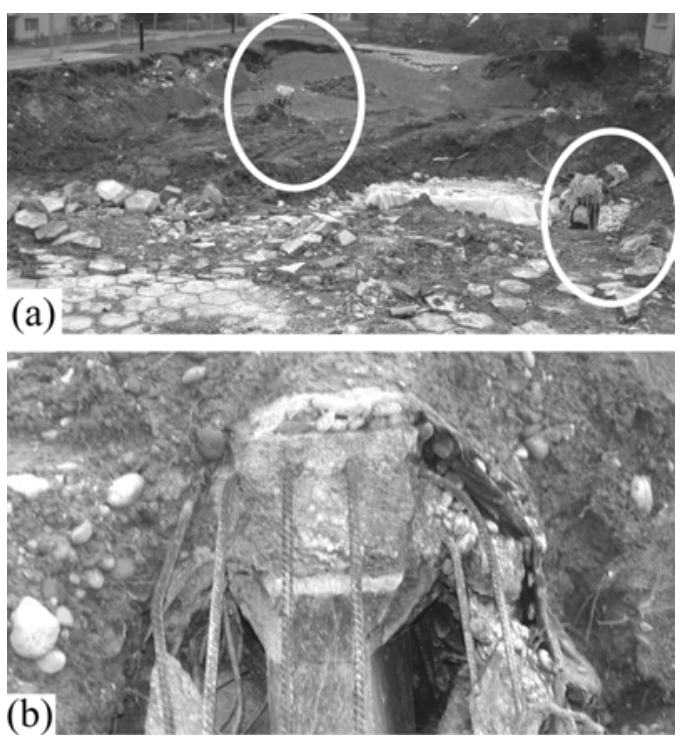

Fig. 1-Collapse of parking garage flat slab at Gretzenbach (Switzerland, 2004): (a) view of flat slab after collapse (with ground cover, columns indicated inside circles); and (b) detail of column after punching.

shown in Fig. 2(a) through (e). They comprise enlargements of the support region (by the addition of column capitals or widening of the columns [refer to Fig. 2(a) through (b)]), strengthening of the flexural reinforcement (by casting a concrete topping or gluing reinforcement [refer to Fig. 2(c) and (d)]), or installing shear reinforcement (refer to Fig. 2(e)). Those possibilities can, however, be impractical in many situations, as they require accessing the upper face of the slab (refer to Fig. 2(c) and (d)), which is usually covered by soil or floor, or enlarging the support region (refer to Fig. 2(a) and (b)), which is not always possible due to architecture and space requirements. In this paper, the performance of an unusual solution, evolved from previous works ${ }^{4}$ and overcoming previous problems, is investigated. The system (refer to Fig. 2(f) and 3) consists of a series of inclined shear reinforcing bars, bonded within an existing slab and installed by drilling holes only from the soffit of the slab. The performance of the system is confirmed by the results of an experimental test program, showing the significant increase both on the punching shear resistance (ensuring

ACI Structural Journal, V. 107, No. 4, July-August 2010

MS No. S-2009-219.R1 received June 26, 2009, and reviewed under Institute publication policies. Copyright (C) 2010, American Concrete Institute. All rights reserved, including the making of copies unless permission is obtained from the copyright proprietors. Pertinent discussion including author's closure, if any, will be published in the May-June 2011 ACI Structural Journal if the discussion is received by January 1, 2011. 
Miguel Fernández Ruiz is a Lecturer and Research Scientist at Ecole Polytechnique Fédérale de Lausanne (EPFL), Lausanne, Switzerland. He received his diploma in civil engineering from the Polytechnical University of Madrid, Madrid, Spain, in 2001 and his PhD from the same university in 2004. His research interests include the serviceability behavior of structures, bond, shear and punching shear, and the modeling of structural concrete using stress fields.

ACI member Aurelio Muttoni is a Professor and Head of the Structural Concrete Laboratory at EPFL. He received his diploma and PhD in civil engineering from the Swiss Federal Institute of Technology, Zurich, Switzerland, in 1982 and 1989, respectively. His research interests include the theoretical basis of the design of reinforced concrete structures, shear and punching shear, fiber-reinforced high-strength concrete, soilstructure interaction, and the conceptual design of bridges.

Jakob Kunz is a Scientific Consultant for anchor and structural rehabilitation applications at Hilti Corporation. He received his PhD in civil engineering from EPFL. His research interests include fastening technology, structural dynamics, and bond in concrete.

sufficient strength) and on the deformation capacity of the slabs (allowing redistribution of internal forces to avoid progressive collapse). Applications of this system have already been performed in various existing flat slabs with excellent results $^{2}$ (refer to Fig. 3(d)-strengthening of flat slabs in Bern main train station, Switzerland).

Finally, the paper discusses a design approach for shear reinforcement based on the critical shear-crack theory (CSCT).$^{5-8}$ This approach is proven to provide a rational basis for its design, being especially convenient to account for the particularities of post-installed shear reinforcement (contrary to the use of most design codes that do not deal with post-installed systems). In design, it allows one to account for the influence of the geometrical and mechanical parameters of the slab (as flexural reinforcement ratio, concrete strength, and others) for those of the post-installed reinforcement (bond strength, bar strength, and anchorage failures), and for the load level of the slab at the time of strengthening.

\section{RESEARCH SIGNIFICANCE}

Many existing flat slabs of buildings or parking garages currently have to be shear-reinforced to satisfy changes in their use or due to more severe code requirements. Conventional reinforcing methods for slabs are, however, not fully satisfying or applicable. This paper introduces an innovative system overcoming most of the previous problems and allowing to reinforce against shear by intervening only on the lower face of the slab. The results of a test program on 12 specimens showed that the system significantly increased both the strength and deformation capacity. A consistent approach for its design is also introduced. This approach is based on the CSCT and allows one to account for for the particularities of post-installed systems.

\section{DESCRIPTION OF POST-INSTALLED SHEAR REINFORCEMENT SYSTEM}

Figure 3(a) shows a cross section of a member reinforced with the investigated system. It consisted of bars installed into inclined holes (hammer-drilled at 45 degrees from the soffit of an existing slab [refer to Fig. 3(d)]) and bonded by a high-performance epoxy adhesive. The diameter of the drill hole was typically $22 \mathrm{~mm}$ (0.86 in.) for the $16 \mathrm{~mm}$ (0.63 in.) diameter bars and $25 \mathrm{~mm}$ (1 in.) for the $20 \mathrm{~mm}$ (0.78 in.) diameter bars. The length of the drilled holes was such that they reached at least the lowest layer of the tensile reinforcement but, typically, holes were drilled up to the level between the two tensile reinforcement layers. The lower anchorage of the reinforcement was eventually

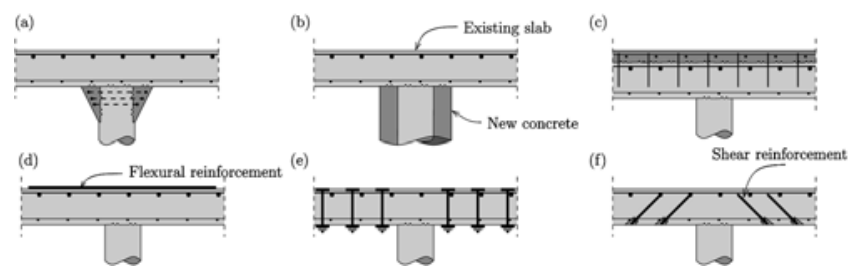

Fig. 2-Reinforcing of existing slabs against punching shear: (a) concreting or installing of steel-precast capital; (b) widening of column; (c) addition of upper concrete layer; (d) addition of glued flexural reinforcement; (e) postinstalled shear reinforcement with mechanical anchorage; and $(f)$ bonded post-installed shear reinforcement.

(a)

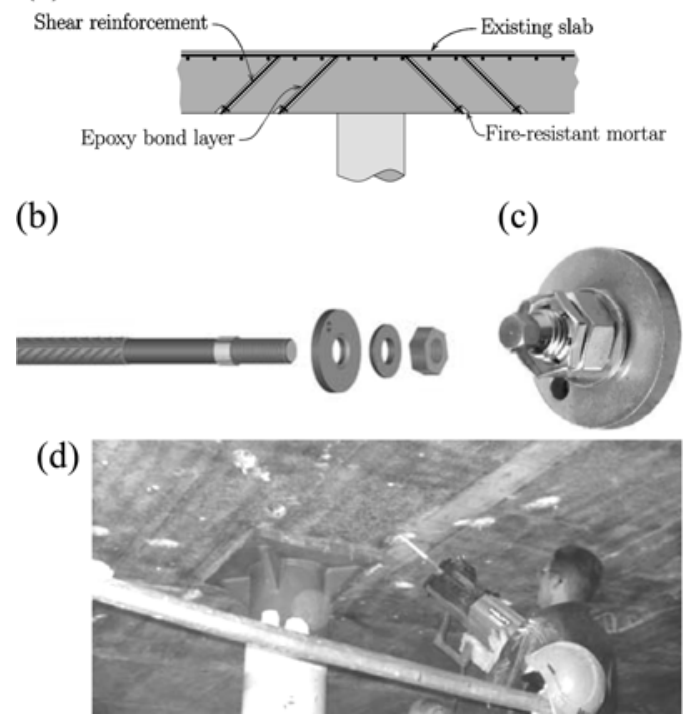

Fig. 3-Post-installed shear reinforcement: (a) typical cross section; (b) view of nut, washers, and bar; (c) detail of anchor head; and $(d)$ installing by drilling of inclined holes.

covered by a fire-resisting mortar for protection and to respect the flat soffit of the slab.

Tension bars were used as shear reinforcement. The bars were 16 or $20 \mathrm{~mm}$ ( 0.63 or 0.78 in.) in diameter with a characteristic yield strength of $500 \mathrm{MPa}(72.4 \mathrm{ksi})$. Once the bars were installed, adhesive $\mathrm{e}^{9,10}$ was injected into the drilled holes, filling the gaps. The average bond strength of the adhesive $\left(\tau_{b}\right)$ was estimated as 9,10

$$
\tau_{b}=18.7 \cdot\left(\frac{f_{c}}{20}\right)^{0.1} \mathrm{MPa} \quad\left(\tau_{b}=2710 \cdot\left(\frac{f_{c}}{2898}\right)^{0.1} \mathrm{psi}\right)
$$

where $f_{c}$ is the compressive strength of the concrete of the slab (measured on the cylinder, the formula was valid between 20 and $50 \mathrm{MPa}$ [2900 and $7200 \mathrm{psi}$ ).

The lower part of the bars (refer to Fig. 3(b) and (c)) consisted of a smooth shaft with a thread M16 or M20 ( 0.63 or 0.78 in.). The smooth shaft and thread were made of steel with a higher yield strength than that of the reinforcement bar and, thus, their strength was never governing.

After curing of the adhesive, the lower thread of the bar was fixed to an anchorage consisting of an injection washer (with a diameter of $52 \mathrm{~mm}$ [2.05 in.] for Shaft M16 or $60 \mathrm{~mm}$ [2.36 in.] for Shaft M20) with a spherical washer (to eliminate 
Table 1 -Main properties of tested specimens ( $V_{\text {test }}$ and $\psi_{\text {test }}$ measured at maximum applied load) and comparison to proposed model

\begin{tabular}{|c|c|c|c|c|c|c|c|c|c|c|c|c|c|c|}
\hline Specimen & $\begin{array}{c}f_{c}, \\
\mathrm{MPa}(\mathrm{psi})\end{array}$ & $\rho, \%$ & $\begin{array}{c}f_{y}, \\
\mathrm{MPa}(\mathrm{ksi})\end{array}$ & $\rho_{w}, \%$ & $n_{r}$ & $n_{a}$ & $\begin{array}{c}s_{0}, \\
\text { mm (in.) }\end{array}$ & $\begin{array}{c}s_{v}, \\
\text { mm (in.) }\end{array}$ & \begin{tabular}{|c|}
$V_{\text {test }}$, \\
$\mathrm{kN}$ (kips) \\
\end{tabular} & $\psi_{\text {test }}, \%$ & $\begin{array}{c}V_{\text {calc }} \\
\mathrm{kN} \text { (kips) } \\
\end{array}$ & $\psi_{\text {calc }}, \%$ & $V_{\text {test }} / V_{\text {calc }}$ & $\psi_{\text {test }} / \psi_{\text {calc }}$ \\
\hline PV1 & $34.0(4900)$ & 1.50 & 709 (102) & - & - & - & - & - & $974(218)$ & 0.76 & 904 (203) & 0.74 & 1.08 & 1.03 \\
\hline PV2 & $35.4(5100)$ & 1.50 & 709 (102) & 0.47 & 8 & 3 & $200(7.87)$ & $200(7.87)$ & $1383(309)$ & 1.40 & $1320(295)$ & 1.30 & 1.05 & 1.08 \\
\hline PV3 & $35.6(5200)$ & 1.50 & 709 (102) & 0.95 & 12 & 3 & $150(5.90)$ & $150(5.90)$ & $1577(353)$ & 2.52 & 1447 (323) & 1.49 & 1.09 & 1.69 \\
\hline PV6 & $33.3(4800)$ & 0.57 & $505(73.2)$ & 0.62 & 8 & 4 & $150(5.90)$ & $150(5.90)$ & $850(190)$ & 4.05 & $827(185)$ & 3.92 & 1.03 & 1.03 \\
\hline PV7 & $33.8(4900)$ & 0.57 & $505(73.2)$ & 0.62 & 8 & 4 & $150(5.90)$ & $150(5.90)$ & $854(191)$ & 3.72 & $828(185)$ & 3.95 & 1.03 & 0.94 \\
\hline PV8 & $34.1(4900)$ & 0.57 & $505(73.2)$ & 0.31 & 4 & 4 & $150(5.90)$ & $150(5.90)$ & $833(186)$ & 2.16 & $827(185)$ & 2.76 & 1.01 & 1.27 \\
\hline PV14 & $36.6(5300)$ & 1.50 & 527 (76.4) & 1.14 & 12 & 6 & $200(7.87)$ & $125(4.92)$ & $1690(378)$ & 2.44 & 1517 (339) & 1.80 & 1.11 & 1.35 \\
\hline PV15 & $36.8(5300)$ & 1.50 & $527(76.4)$ & 0.95 & 12 & 6 & $150(5.90)$ & $150(5.90)$ & $1609(360)$ & 3.11 & 1519 (339) & 1.80 & 1.06 & 1.72 \\
\hline PV16 & $37.2(5400)$ & 1.50 & $527(76.4)$ & 0.35 & 6 & 4 & $200(7.87)$ & $200(7.87)$ & $1263(283)$ & 1.18 & $1195(267)$ & 1.26 & 1.06 & 0.94 \\
\hline PV17 & $29.9(4300)$ & 1.50 & $518(75.0)$ & 0.24 & 4 & 4 & $200(7.87)$ & $200(7.87)$ & $1121(251)$ & 0.88 & $1040(232)$ & 1.02 & 1.08 & 0.86 \\
\hline PV18 & $28.2(4000)$ & 1.00 & $518(75.0)$ & 0.35 & 6 & 4 & $200(7.87)$ & $200(7.87)$ & $1070(239)$ & 1.55 & $1013(227)$ & 1.62 & 1.06 & 0.96 \\
\hline PV19 & $29.2(4200)$ & 1.00 & $518(75.0)$ & 0.24 & 4 & 4 & $200(7.87)$ & $200(7.87)$ & $1075(241)$ & 1.31 & 919 (206) & 1.40 & 1.17 & 0.94 \\
\hline \multirow{2}{*}{ 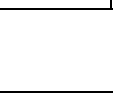 } & & & & & & & & & & & & Average & 1.07 & 1.15 \\
\hline & & & & & & & & & & & & $\mathrm{CoV}$ & 0.04 & 0.26 \\
\hline
\end{tabular}

bending of the bar) and a nut. To create a slip-free anchorage, and due to the fact that the drilled surface to which the washer was applied was rough, the annular gaps after installing were filled through the injection washer with the same epoxy adhesive used for the bar. The nuts were tightened to the installation torque of $100 \mathrm{Nm}(73.7 \mathrm{ft}-\mathrm{lb})$. The goal of tightening the nut was to achieve the best possible anchorage of the reinforcement, that is, to avoid any slackness as far as possible. For the tests presented in this paper, after the application of the $100 \mathrm{Nm}$ (73.7 ft-lb) torque, the torque was completely released and the nut was retightened by hand to a minimum torque before the load was applied to the slab.

\section{EXPERIMENTAL PROGRAM}

A series of 12 slabs was tested to investigate the performance of slabs with the previously described post-installed shear reinforcement.

\section{Specimens}

A summary of the main properties of the specimens is given in Table 1. The geometrical dimensions were kept constant for the series. Specimens were $3.0 \times 3.0 \mathrm{~m}(118 \mathrm{x}$ 118 in.) in plan with a thickness of $250 \mathrm{~mm}$ (9.84 in). Specimens were loaded through a square steel plate $260 \mathrm{x}$ $260 \mathrm{~mm}(10.2 \times 10.2 \mathrm{in}$.) placed at the center of the specimen by using a hydraulic jack pushing upwards (refer to Fig. 4). The load was supported at eight points (distance of the center of gravity of the support regions to the center of the slab equal to $1560 \mathrm{~mm}$ [61.4 in.]), which transmitted their reaction by means of four spreaders to four tensile bars anchored in the strong floor (refer to Fig. 4).

The flexural reinforcement ratio of the specimens $(\rho)$ was $1.50,1.00$, and $0.57 \%$ (refer to Table 1 ). The effective depth (d) was constant and equal to $210 \mathrm{~mm}(8.26 \mathrm{in}$. [refer to Fig. 5]). The same reinforcement layout as other tests performed by the authors ${ }^{11}$ was used.

The diameter of the shear reinforcement was equal to $16 \mathrm{~mm}$ (0.63 in.) for all shear-reinforced specimens. Different arrangements of shear reinforcement (the number and position of bars) were investigated. The geometrical parameters defining them are shown in Fig. 5 and Table 1. In the paper, reference will be made to the shear reinforcement ratio $\rho_{w}$, which will be defined as
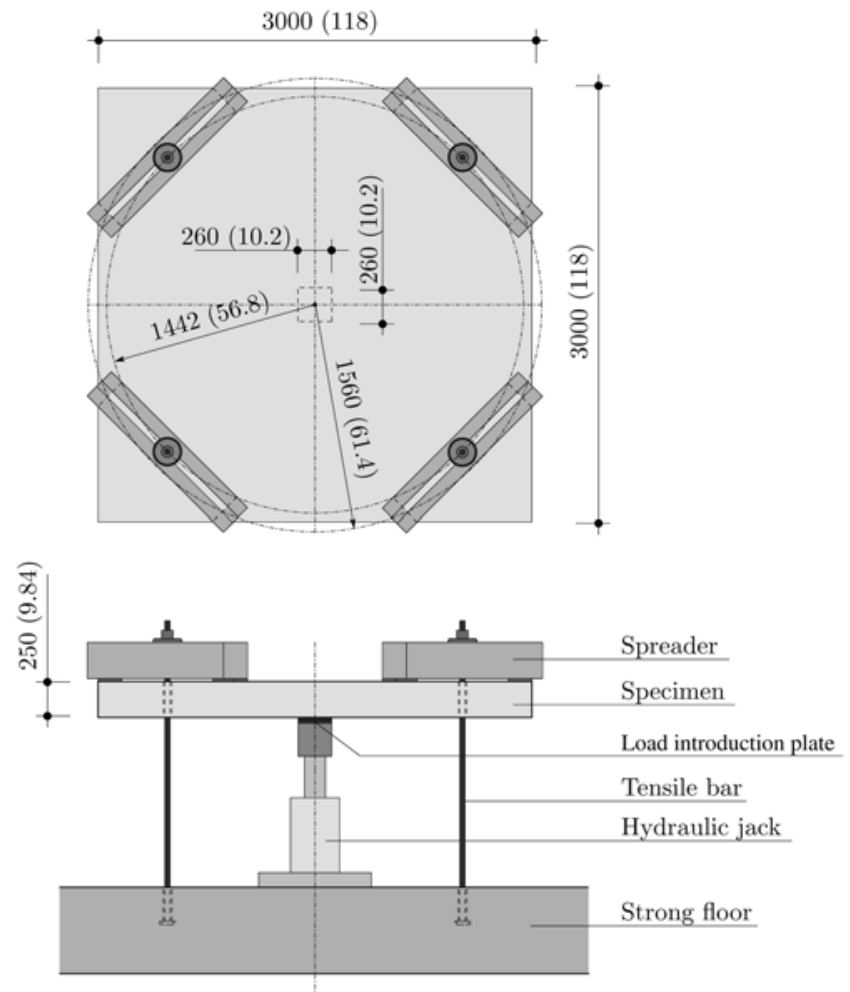

Fig. 4-Test setup (dimensions in mm [in.]).

$$
\rho_{w}=\frac{n_{r} \cdot \frac{\pi}{4} \cdot d_{b}^{2}}{s_{v} \cdot b_{0}}
$$

where $n_{r}$ is the number of radii of shear reinforcement, $d_{b}$ is the shear reinforcement diameter (16 mm [0.63 in.]), $s_{v}$ is the distance between two adjacent reinforcements in the radial direction (refer to Fig. 5), and $b_{0}$ is the length of a control perimeter at $d / 2$ of the border of the support region $(1.70 \mathrm{~m}$ [66.9 in.]).

The shear reinforcement ratio varied between 0.24 and $1.14 \%$, ranging from light to heavy shear reinforcement conditions. Also, a reference test (Slab PV1) was performed 
(a)
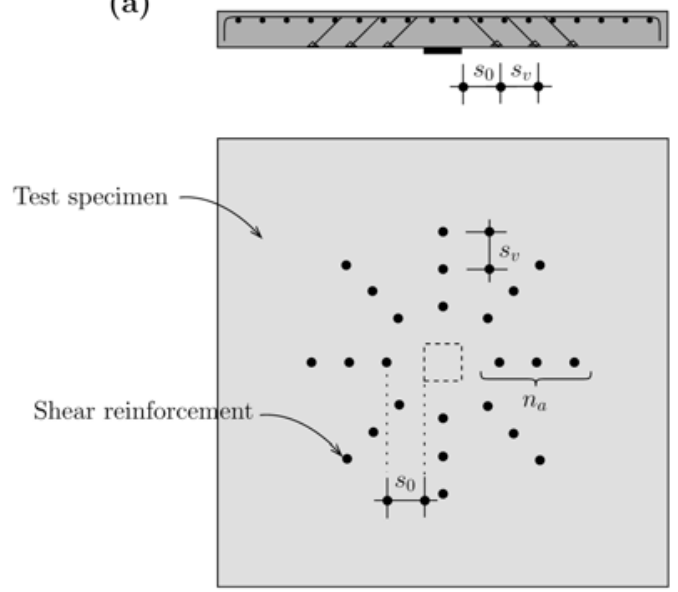

(b)

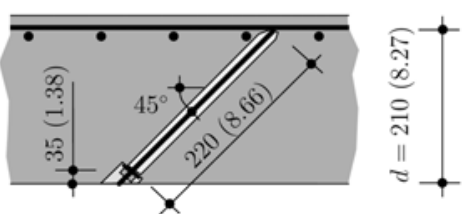

Fig. 5-Layout of post-installed shear reinforcement: (a) cross section and plan view; and $(b)$ dimensions of shear reinforcement (dimensions in $\mathrm{mm}$ [in.]).
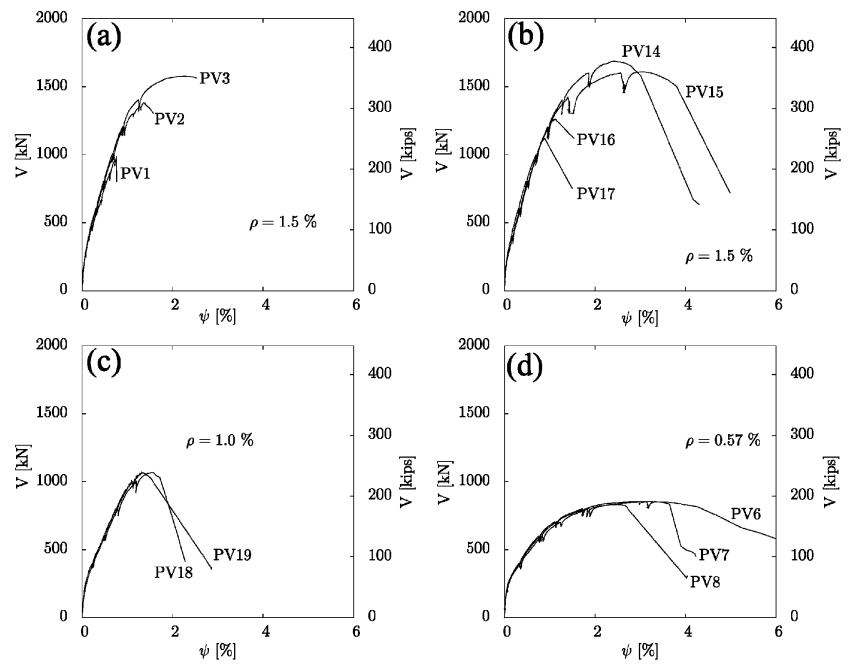

Fig. 6-Load-rotation curves of: (a) Tests PVI through PV3; (b) Tests PV14 through PVI7; (c) Tests PV18 and PV19; and (d) Tests PV6 through PV8.

without shear reinforcement. The lower anchorage head of the shear reinforcement was embedded into the slab for all specimens except for Slab PV7, where they were installed on the concrete surface.

\section{Material properties}

Normal-strength concrete with a water-cement ratio $(w / c)$ equal to 0.69 was used in all of the specimens. Concrete properties (compressive strength and tensile strength) were measured on cubes and cylinders. The results of the compressive strength of concrete (on cylinder, average values) are detailed in Table 1 . The maximum size of the aggregate was $16 \mathrm{~mm}$ (0.63 in.) for all specimens.

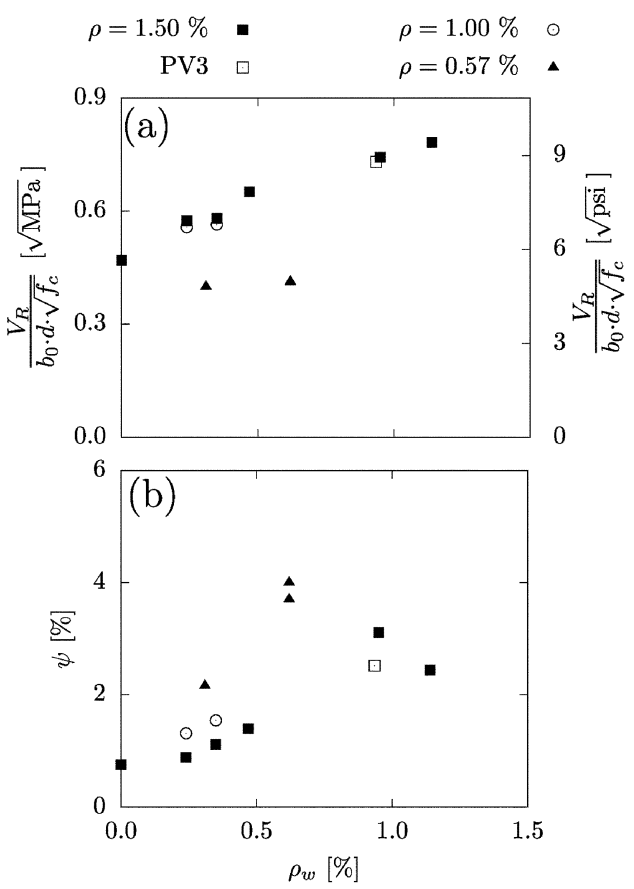

Fig. 7-Test results as function of transverse shear reinforcement $\rho_{\mathrm{w}}$ and flexural reinforcement ratio $\rho$ (all tests failing within shear reinforced zone except Test PV3 [ $\rho=1.5 \%]$ failing outside shear reinforced zone): (a) shear strength; and (b) rotation at maximum load.

Flexural reinforcement of Slabs PV1 through PV3 was high-strength (hot-rolled) with a measured yield strength of $709 \mathrm{MPa}(102 \mathrm{ksi})$. The rest of the specimens used conventional steel (cold-worked for Slabs PV6 through PV8 and hotrolled for Slabs PV14 through PV19) with yield strengths ranging between 505 and $527 \mathrm{MPa}$ (73.2 and $76.4 \mathrm{ksi}$ ) (refer to Table 1). The average yield strength for shear reinforcement was $547 \mathrm{MPa}(79.3 \mathrm{ksi})$.

\section{Measurements}

Various continuous measurements were performed during the tests, including measurement of the applied load (taken by an integrated load cell at the hydraulic jack) and measurements of the deflection of the slab on the top surface. In addition to the continuous measurements, crack patterns at the top surface were recorded at selected load stages and, after testing, slabs were saw cut.

\section{Development of tests}

The load-rotation curves measured for the various specimens are plotted in Fig. 6. Rotations were calculated as the average slope of the slab. Tests with the lowest flexural reinforcement ratios (Slabs PV6 through PV8, $\rho=0.57 \%$ [refer to Fig. 6(d)]) failed after the development of large rotations with significant crack widths (indicating extensive yielding of the flexural reinforcement). The maximum load was thus governed by bending. The slabs eventually punched, however, which limited the deformation capacity of the members (this result is in agreement with what was reported in other experimental studies ${ }^{11}$ ). This can be seen in Fig. 7(b), where the rotations of the slabs at maximum load are plotted as a function of the shear reinforcement amount. Although the maximum failure load remained approximately constant for the three specimens, the rotation capacity increased significantly for specimens 

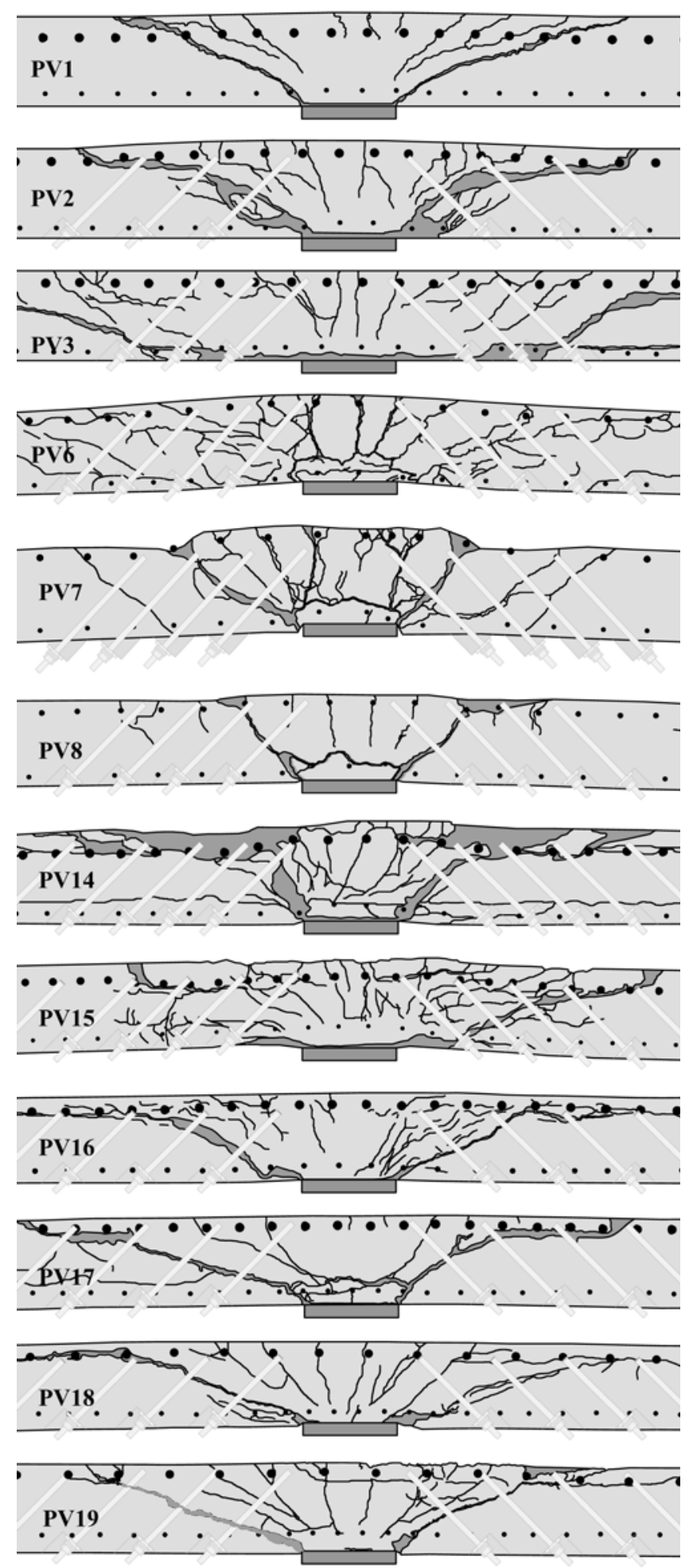

Fig. 8-Cracking patterns after saw cut (detail near support region).

with larger shear reinforcement ratios. With respect to Slabs PV6 and PV7, both had the same flexural and shear reinforcement ratios. The lower anchorage of shear reinforcement for Slab PV7 was, however, performed by means of steel plates placed outside the slab (instead of being embedded within the slab) (refer to Fig. 8). No significant difference on the strength or deformation capacity of both specimens was noticed.
Two tests were performed with moderate flexural reinforcement ratios (Slabs PV18 and PV19, $\rho=1 \%$ [refer to Fig. 6(c)]). Shear reinforcement was light in both specimens and tests failed by punching in a rather brittle manner prior to the development of a flexural mechanism. In this case (refer to Fig. 7), with an increasing amount of shear reinforcement, the deformation capacity not only increased at failure but also increased in the normalized strength of the slabs $\left(V_{R} / \sqrt{f_{c}}\right)$.

For tests with the largest amount of flexural reinforcement (Slabs PV1 through PV3 and PV14 through PV17, $\rho=1.5 \%$ [refer to Fig. 6(a) and (b)]), the behavior was largely influenced by the amount of shear reinforcement. The reference test (Slab PV1, with no shear reinforcement) failed in a very brittle manner. The strength and deformation capacity increased consistently for the other tests with the amount of shear reinforcement (refer to Fig. 7). Slab PV3, with a heavy shear reinforcement concentrated only near the column (refer to Table 1), failed by punching outside the shear-reinforced zone (refer to Fig. 8). Two other slabs, (PV14 and PV15) with heavy shear reinforcement covering a large area, failed by punching near the column with crushing of the compression struts (refer to Fig. 8). From the two tests, Slab PV14 showed larger strength. This was due to the fact that anchorages of the shear reinforcement were placed beyond those of Slab PV15 (refer to Table 1 and Fig. 8), leading to more limited stress concentrations in the compression-critical region. Crack patterns, after saw-cutting of the slabs, are also interesting for this series $(\rho=1.5 \%)$ (refer to Fig. 8). The reference test (Slab PV1) shows one single crack localizing strains (same as Slab PV3 outside the shear-reinforced region). Cracks are progressively smeared as the amount of shear reinforcement increases at the column region. For Slab PV2, pullout cracks at the anchorages of the shear reinforcement ${ }^{8}$ were also clearly observed.

\section{APPLICATIONS OF CSCT TO DESIGN OF SHEAR REINFORCEMENT}

The design of the post-installed shear reinforcement can be performed on the basis of the CSCT. So far, this theory has been successfully applied to a number of shear reinforcing systems installed prior to the concreting of slabs ${ }^{8}$ (such as stirrups, studs, or prestressed bars). As will be shown, the application of the CSCT is very convenient to evaluate the behavior and strength of post-installed shear reinforcement. In this paper, reference will be made to formulas allowing for the estimation of the average behavior of shear-reinforced slabs. Design formulas based on this approach, but accounting for characteristic values of strength and failure criteria as well as for safety factors, have been detailed in the Appendix of this paper.

For the system investigated in this paper, failure in punching can occur by three different modes according to the CSCT: crushing of the concrete struts near the support region, punching within the shear reinforced zone, and punching outside the shear reinforced zone.

$$
V_{R}=\min \left(V_{R, \text { crush }} ; V_{R, \text { in }} ; V_{R, \text { out }}\right)
$$

If none of the former failure modes develop prior to reaching the flexural strength of the slab, bending will govern the strength of the specimen. ${ }^{11}$

Failure is estimated according to the CSCT when the loadrotation curve of the slab intersects the governing failure criterion. ${ }^{6}$ This allows for the calculation of both the strength 
(a)

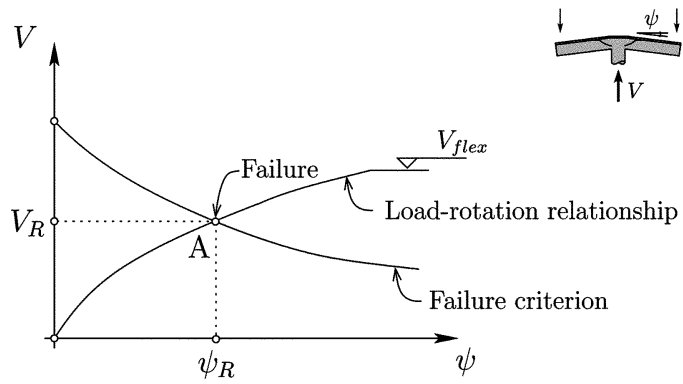

(b)

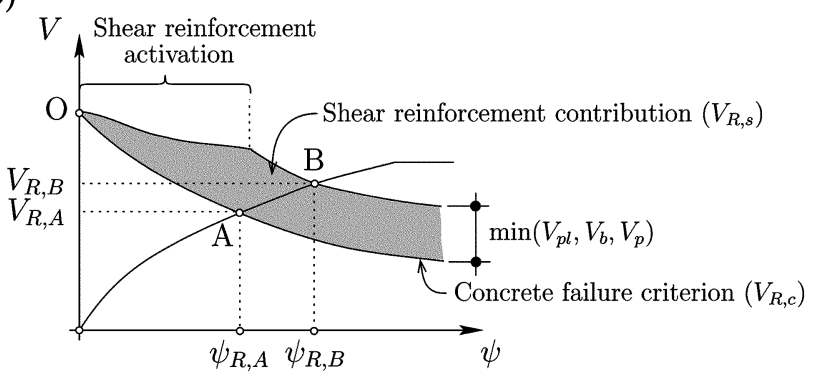

(c)

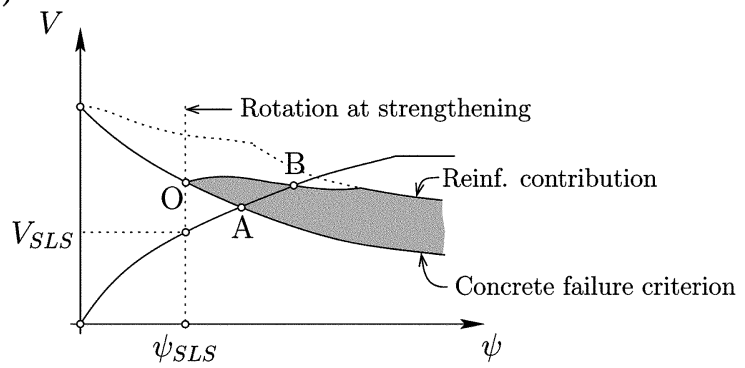

Fig. 9-Calculation of failure according to critical shearcrack theory: (a) slab without shear reinforcement; (b) contribution of shear reinforcement to punching shear strength (strengthening on unloaded slab); and (c) strengthening on slab subjected to given load.

$\left(V_{R}\right)$ and deformation $\left(\psi_{R}\right)$ of the slab at failure (refer to Point A in Fig. 9(a)). To characterize the load-rotation curve of the slab, the following semi-analytical expression was proposed by Muttoni ${ }^{6}$ (obtained from a number of simplifications from a more general theoretically derived one)

$$
\psi=1.5 \cdot \frac{r_{s}}{d} \cdot \frac{f_{y}}{E_{s}} \cdot\left(\frac{V}{V_{\text {flex }}}\right)^{\frac{3}{2}} \text { if } V \leq V_{\text {flex }}
$$

where $\psi$ is the rotation of the slab, $r_{s}$ is the distance from the axis of the column to the line of contraflexure of bending moments (that, for regular flat slabs, can be taken equal to $0.22 \ell$, where $\ell$ is the span length of the flat slab), $f_{y}$ is the yield strength of the flexural reinforcing steel, $d$ is the effective depth of the slab, $E_{s}$ is the modulus of elasticity of the flexural reinforcing steel, and $V_{\text {flex }}$ is the load necessary to develop the flexural mechanism of the slab (detailed solutions for the latter can be found in the literature $\left.{ }^{11,12}\right)$. For the case of bonded post-installed shear reinforcement, the following failure criteria can be adopted.

\section{Punching within shear reinforced zone}

When a single crack localizes strains within the shear reinforced zone, shear strength can be estimated as ${ }^{8}$

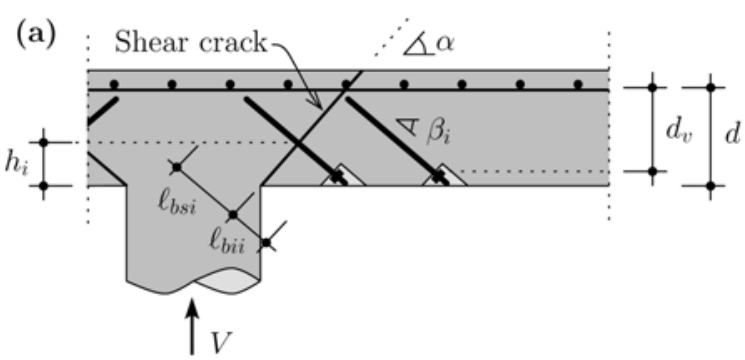

(b)

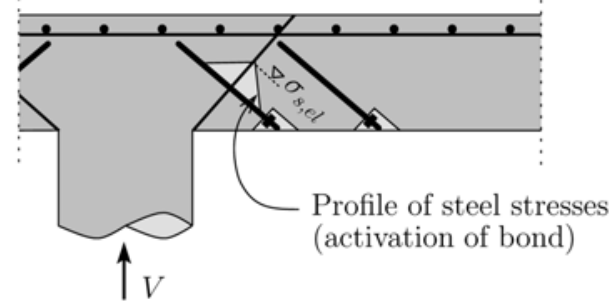

(c)

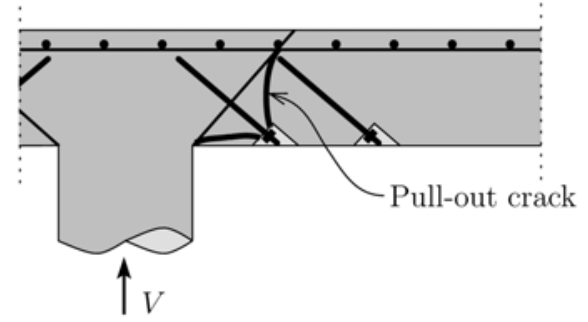

Fig. 10-Development of shear reinforcement: (a) geometrical parameters; (b) shear reinforcement stress during activation phase; and (c) pullout of lower anchorage plates.

$$
V_{R, \text { in }}=V_{R, c}+V_{R, s}
$$

where $V_{R, c}$ and $V_{R, s}$ are the concrete and shear reinforcement contributions, respectively (refer to Fig. 9(b)). With respect to the behavior of a slab without shear reinforcement (Point A of Fig. 9(b)), both the strength and deformation capacity can be increased by adding shear reinforcement (Point $\mathrm{B}$ of Fig. 9(b)). Concrete contribution can be obtained from the failure criterion of slabs without shear reinforcement, ${ }^{8}$ which is given by the following expression ${ }^{6}$

$$
V_{R, c}=\frac{3}{4} \cdot \frac{b_{0, i n} \cdot d \cdot \sqrt{f_{c}}}{1+15 \cdot \frac{\psi \cdot d}{d_{g 0}+d_{g}}}
$$

where, for customary units (psi, in.), coefficient $3 / 4$ has to be replaced by $9, d_{g}$ is the maximum aggregate size, $d_{g 0}$ is a reference aggregate size (equal to $16 \mathrm{~mm}$ [0.63 in.]) and $b_{0, \text { in }}$ is the control perimeter (defined at $d / 2$ of the edge of the support region). With respect to the shear reinforcement contribution (Fig. 9(b)), its value can be estimated as

$$
V_{R, s}=\sum_{i=1}^{n} \sigma_{s i}(\psi) \cdot A_{s w i} \cdot \sin \left(\beta_{i}\right)
$$

where $A_{s w i}$ is the cross-sectional area of the shear reinforcement, $\beta$ is the angle of shear reinforcement (refer to Fig. 10, $\pi / 4$ in this case), and $\sigma_{s}(\psi)$ is the stress in the reinforcement developed for a given rotation. 
The stress in the shear reinforcement $\left(\sigma_{s}\right)$ is calculated on the basis that, as a slab deforms, cracks open progressively and the stress in the shear reinforcement increases (activation phase, refer to Fig. 10(b)). This is valid until a maximum value of the stress is reached. For bonded bars, the following expression is proposed

$$
\sigma_{s}=\min \left(\sigma_{s, e l} ; \sigma_{s, b} ; \sigma_{s, p} ; f_{y w}\right)
$$

where $\sigma_{s, e l}$ is the stress during the activation phase, $\sigma_{s, b}$ is the maximum stress that can be developed by bond, $\sigma_{s, p}$ is the maximum stress that can be developed by pullout of the lower anchorages, and $f_{y w}$ is the yield strength of the steel. Assuming a rigid-plastic law for bond (refer to Fig. 10(b)), $\sigma_{s, e l}$ can be calculated prior to yielding as ${ }^{13}$

$$
\sigma_{s, e l}=\sqrt{\frac{4 \cdot \tau_{b} \cdot E_{s} \cdot w_{b}}{d_{b}}}
$$

where $w_{b}$ is the opening of the critical shear crack at the level of the shear reinforcement. According to the CSCT hypotheses, such an opening can be related to the rotation of the slab as 8

$$
w_{b}=0.5 \cdot \psi \cdot h_{i} \cdot \cos \left(\alpha+\beta_{i}-\frac{\pi}{2}\right)
$$

where $h_{i}$ is the height at which the critical shear crack intersects the shear reinforcement (refer to Fig. 10(a)) and $\alpha$ is the angle of the critical shear crack (where a value giving good fit to test results ${ }^{8}$ is $\pi / 4$ ). Activation of the bar occurs by bond ends when the bar reaches one of the following conditions:

1. $\sigma_{s}=f_{y w}$, meaning that the bar has reached its yield strength;

2. $\sigma_{s}=\sigma_{s b}=4 \tau_{b} \ell_{b s i} / d_{b}$ (where $\ell_{b s i}$ is defined in Fig. 10(a)), meaning that bar has reached its maximum bond capacity (slip at the upper end of the bar); and

3. $\sigma_{s}=\sigma_{s p}$, meaning that bottom anchorages of the bar are pulled out (refer to Fig. 10(c)).

With respect to the latter limit (pullout of bottom anchorages), the strength of this failure mode can be estimated as

$$
\sigma_{s p}=19 \cdot \sqrt{f_{c}} \cdot \frac{\ell_{b i i}^{1.5}}{d_{b}^{2}} \cdot\left(1+\frac{d_{i n f}}{\ell_{b i i}}\right) \quad[\mathrm{N}, \mathrm{mm}]
$$

where the coefficient 19 has to be replaced by 46 where customary units are used (psi, in.). Parameter $\ell_{b i i}$ is defined in Fig. 10(a) and $d_{i n f}$ is the diameter of the anchoring plate. This formula is grounded on the concrete capacity design theory, ${ }^{14}$ but considers the influence of the anchorage size according to ACI $349-85^{15}$ (by the inclusion of the factor $\left.\left(1+d_{\text {inf }} / \ell_{\text {bii }}\right)\right)$.

It can be noted that, according to the CSCT approach, high bond strength (as provided by the epoxy adhesive used in the tests) is required between shear reinforcement and the slab to develop large tensile stresses in the bar for limited rotations (refer to Eq. (9)). Also, the fact that the bars are inclined is very convenient as the development and anchorage lengths $\left(\ell_{b i s}\right.$ and $\ell_{b i i}$, respectively) can be increased by a factor $1 / \sin (\beta)$ with respect to vertical bars. In this sense, the chosen value for angle $\beta$ (45 degrees) is a good compromise between an increase in development lengths and the efficiency in carrying shear (refer to Eq. (7)).

It is also interesting to note (Fig. 9(b)) that, as rotations increase by the addition of shear reinforcement, the concrete contribution diminishes. In codes of design, the reduction on concrete contribution is also usually acknowledged, but accepts a constant value for it (for instance, a $50 \%$ reduction in ACI $318-08^{16}$ or a $25 \%$ reduction in EC- $2^{17}$ ). The approach of the CSCT has the advantage that the actual decrease on concrete contribution can be estimated depending on the conditions and amount of shear reinforcement of each case. In addition, the level of deformation of the slab at the time of strengthening (which depends on the applied load) can be accounted in the approach of the CSCT, limiting in some cases the total strength (and deformation capacity) of the member. This fact is shown in Fig. 9(c), where the slab is subjected to a given rotation $\left(\psi_{S L S}\right)$ as a consequence of the actual load at the time of strengthening $\left(V_{S L S}\right)$. This rotation has to be considered in the development of strength of the shear reinforcement during the activation phase by deducing it from the actual rotation (refer to Fig. 9(c)). This consideration, which is instrumental in post-installed systems, is currently not included in design codes, which are mostly focused on the design of new slabs.

\section{Punching outside shear-reinforced zone}

Outside the shear-reinforced zone, shear strength depends only on the concrete contribution. It can thus be estimated as

$$
V_{R, \text { out }}=\frac{3}{4} \cdot \frac{b_{0, \text { out }} \cdot d_{v} \cdot \sqrt{f_{c}}}{1+15 \cdot \frac{\psi \cdot d}{d_{g 0}+d_{g}}}[\mathrm{~N}, \mathrm{~mm}]
$$

where, for customary units (psi, in.), the coefficient 3/4 has to be replaced by $9, d_{v}$ is the reduced effective depth shown in Fig. 10(a) (to account for pull-out of the outer shear reinforcement ${ }^{8}$ ), and $b_{0, \text { out }}$ is the control perimeter (defined at $d / 2$ of the outer layer of shear reinforcement and, considering for post-installed bars, $2 d$ as the maximum effective distance between two concentric rows of shear reinforcement).

\section{Crushing of concrete struts}

The compressive strength of compression struts is strongly influenced by the state of transverse strains in the shear-critical region. ${ }^{18,19}$ As rotations increase, crack widths (and strains) become larger in the region near the column. Therefore, the strength of concrete struts is reduced. On that basis, the crushing strength of a reinforced concrete slab can be estimated by using the failure criterion of slabs without shear reinforcement (which is a function of the rotations of the slab) but multiplied by $\lambda(>1)$

$$
V_{R, \text { crush }}=\lambda \cdot \frac{3}{4} \cdot \frac{b_{0, i n} \cdot d \cdot \sqrt{f_{c}}}{1+15 \cdot \frac{\psi \cdot d}{d_{g 0}+d_{g}}}
$$

where for customary units (psi, in.), the coefficient 3/4 has to be replaced by 9 . For slabs reinforced with post-installed bars, and accounting for the tests presented in this paper, $\lambda$ is proposed to be set to 2.6 . 
(a)

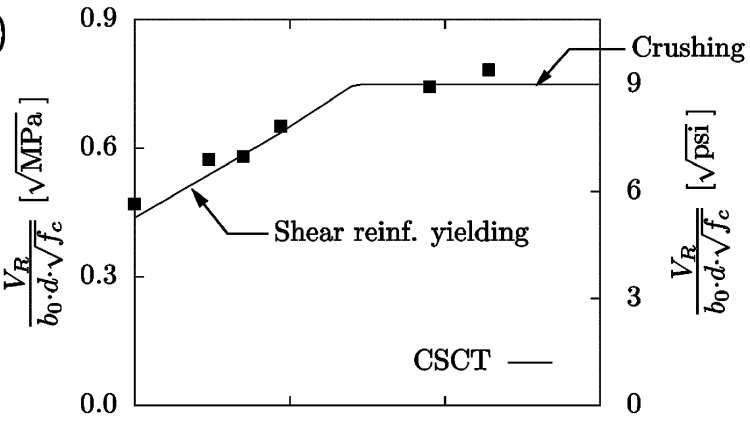

(b)

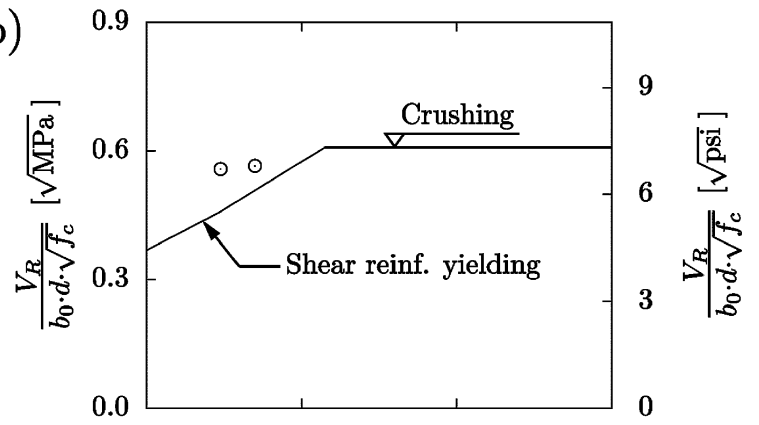

(c)

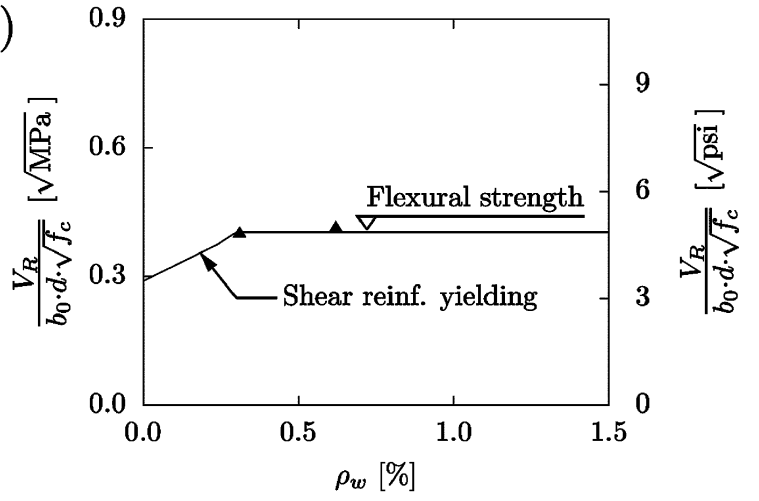

Fig. 11-Comparison of test results and critical shear-crack theory $\left(\mathrm{f}_{\mathrm{c}}=30 \mathrm{MPa}[4300 \mathrm{psi}], \mathrm{d}_{\mathrm{g}}=16 \mathrm{~mm}[0.63 \mathrm{in}],. \mathrm{f}_{\mathrm{y}}=\right.$ $510 \mathrm{MPa}[73.9 \mathrm{ksi}]$, and $\mathrm{f}_{\mathrm{yw}}=550 \mathrm{MPa}[79.7 \mathrm{ksi}]$ ): (a) $\rho=$ $1.5 \%$ (Tests PV1 and PV2 and PV14 through PV17); (b) $\rho=$ $1.0 \%$ (Tests PV18 and PV19); and (c) $\rho=0.57 \%$ (Tests PV6 through PV8).

\section{ANALYSIS OF TEST RESULTS}

The previous approach based on the CSCT can be applied to estimate the behavior and strength of the tests performed within this research. The results obtained are detailed in Table 1. The CSCT predictions show an excellent agreement, with an average value of the ratio between the measured-topredicted failure load of 1.07 and with a very small value of the coefficient of variation (COV) (4\%). In addition, the various failure modes observed are correctly reproduced. Rotations are also satisfactorily estimated, with safer estimates for specimens where a deformation plateau was developed close to the maximum load (Slabs PV3, PV14, and PV15) (refer to Table 1).

A comparison between theoretical predictions and measured values can be further observed in Fig. 11. The CSCT shows an increase in the strength as the shear reinforcement ratio increases but is limited by the crushing of the struts (series with $\rho=1.5 \%$ or $1.0 \%$ ) or by flexure (series with $\rho=$ $0.57 \%$ ). This result is in accordance to what is observed in the tests, and the trends observed for the various series are suitably reproduced.

\section{CONCLUSIONS}

This paper investigates the shear strengthening of existing slabs with an innovative system consisting of bonded bars post-installed within the slab. The results of an experimental program, as well as a series of theoretical works grounded on the critical shear crack theory, show the following:

1. Inclined bonded bars are an effective way to reinforce existing slabs against punching shear. This leads to economic solutions where only the soffit of the slab has to be accessible.

2 . The strengthening concept is validated through an experimental program performed on 12 specimens with various reinforcement ratios and shear strengthening arrangements. Experimental results show that both the strength and the deformation capacity can significantly be increased at failure with respect to slabs without shear reinforcement.

3. The shear failure of slabs reinforced with this system can develop by crushing concrete struts, punching within the shear reinforced zone, and punching outside the shear reinforced zone. For slabs with low flexural reinforcement ratios, the development of a plastic mechanism is also possible if sufficient shear reinforcement is provided.

4. A consistent design concept based on the critical shear crack is provided for this system. It accounts for the various failure modes and allows considering (amongst others) the influence of bond, anchorage dimensions, and rotations of the slab on the strength of the member at the time of reinforcing.

5. Based on this theory, it is shown that to enhance efficiency of such a system, high bond strength between the bars and the slab is required. Also, using inclined bars helps developing their strength as bond and anchorage lengths increase.

\section{REFERENCES}

1. Muttoni, A.; Fernández Ruiz, M.; Fürst, A.; Guandalini, S.; Hunkeler, F.; Moser, K.; and Seiler, H., "Structural Safety of Parking Garages," Documentation D 0226 SIA, Swiss Society of Engineers and Architects, Zürich, Switzerland, 2008, 105 pp.

2. Kunz, J.; Fernández Ruiz, M.; and Muttoni, A., Enhanced Safety with Post-Installed Punching Shear Reinforcement, fib Symposium, Amsterdam, The Netherlands, CRC Press, 2008, pp. 679-684.

3. ACI Committee 364, "Increasing Shear Capacity Within Existing Reinforced Concrete Structures (ACI 364.2T-08)," American Concrete Institute, Farmington Hills, MI, 2008, 4 pp.

4. Hassanzadeh, G., "Strengthening of R/C Flat Slabs Against Punching Shear," master of civil engineering thesis, KTH, Institutionen för byggkonstruktion, TRITA-BKN, Rapport 41, Stockholm, Sweden, 1996, 134 pp.

5. Muttoni, A., and Schwartz, J., "Behavior of Beams and Punching in Slabs without Shear Reinforcement," IABSE Colloquium, V. 62, Zurich, Switzerland, 1991, pp. 703-708.

6. Muttoni, A., "Punching Shear Strength of Reinforced Concrete Slabs without Transverse Reinforcement," ACI Structural Journal, V. 105, No. 4, July-Aug. 2008, pp. 440-450.

7. Muttoni, A., and Fernández Ruiz, M., "Shear Strength of Members without Transverse Reinforcement as a Function of the Critical Shear Crack Width," ACI Structural Journal, V. 105, No. 2, Mar.-Apr. 2008, pp. 163-172.

8. Fernández Ruiz, M., and Muttoni, A., "Applications of Critical Shear Crack Theory to Punching of Reinforced Concrete Slabs with Transverse Reinforcement," ACI Structural Journal, V. 106, No. 4, July-Aug. 2009, pp. 485-494.

9. European Technical Approval ETA-04/0027, “Injection System Hilti HIT-RE 500," Deutsches Institut für Bautechnik, Berlin, Germany, 2009, $30 \mathrm{pp}$.

10. Hilti Corp., "Hilti Fastening Technology Manual B 2.11," Hilti Corp., FL-9494, Schaan, Principality of Liechtenstein, 2005, 384 pp.

11. Guandalini, S.; Burdet, O.; and Muttoni, A., "Punching Tests of Slabs with Low Reinforcement Ratios," ACI Structural Journal, V. 106, No. 1, Jan.-Feb. 2009, pp. 87-95.

12. Nielsen, M. P., Limit Analysis and Concrete Plasticity, second edition, CRC Press, Boca Raton, FL, 1999, 908 pp.

13. Fernández Ruiz, M.; Muttoni, A.; and Gambarova, P. G., "Analytical Modeling of the Pre- and Post-Yield Behavior of Bond in Reinforced 
Concrete," Journal of Structural Engineering, ASCE, V. 133, No. 10, Oct. 2007, pp. 1364-1372.

14. Fuchs, W.; Eligehausen, R.; and Breen, J. E., "Concrete Capacity Design (CCD) Approach for Fastening to Concrete," ACI Structural Journal, V. 92, No. 1, Jan.-Feb. 1995, pp. 73-94.

15. ACI Committee 349, "Code Requirements for Nuclear Safety Related Structures (ACI 349-85) (Revised 1990) (Reapproved 1997)," American Concrete Institute, Farmington Hills, MI, 1997, 134 pp.

16. ACI Committee 318, "Building Code Requirements for Structural Concrete (ACI 318-08) and Commentary," American Concrete Institute, Farmington Hills, MI, 2008, 473 pp.

17. EN 1992-1-1, "Eurocode 2: Design of Concrete Structures-Part 1-1: General Rules and Rules for Buildings," CEN, Brussels, Belgium, 2004, $225 \mathrm{pp}$.

18. Vecchio, F. J., and Collins, M. P., "The Modified Compression Field Theory for Reinforced Concrete Elements Subjected to Shear," ACI JouRnal, Proceedings V. 83, No. 2, Mar.-Apr. 1986, pp. 219-231

19. Muttoni, A.; Schwartz, J.; and Thürlimann, B., Design of Concrete Structures with Stress Fields, Birkhaüser, Switzerland, 1997, 145 pp.

20. Muttoni, A., and Fernández Ruiz, M., "Design Method for PostInstalled Punching Shear Reinforcement with Hilti Tension Anchors HZA-P,' Report 06-A01-R1b, Ecole Polytechnique Fédérale, Lausanne, Switzerland, 2007, 13 pp.

\section{APPENDIX-DESIGN FORMULAS FOR HZA PUNCHING SHEAR REINFORCEMENT SYSTEM}

The equations presented within the paper use average values with respect to failure criteria ${ }^{6,8}$ and material properties (strength of concrete, steel, and bond). This approach allows direct comparisons to test results. For design purposes, however, they have to be modified by introducing characteristic properties for materials and failure criteria (strength target $5 \%$ fractile) as well as considering safety factors. The three same governing failure modes will be considered.

$$
V_{R, d}=\min \left(V_{R, \text { crush }, d} ; V_{R, \text { in }, d} ; V_{R, \text { out }, d}\right)
$$

\section{Punching within shear reinforced zone}

The design strength of a member within the shear reinforced zone can be calculated as

$$
V_{R, i n, d}=V_{R, c, d}+V_{R, s, d}
$$

where the design concrete contribution is ${ }^{6}$

$$
V_{R, c, d}=\frac{2}{3 \cdot \gamma_{c}} \cdot \frac{b_{0, i n} \cdot d \cdot \sqrt{f_{c k}}}{1+20 \cdot \frac{\psi \cdot d}{d_{g 0}+d_{g}}}
$$

For customary units (psi, in.), the coefficient $2 /\left(3 \gamma_{c}\right)$ has to be replaced by $8 \phi_{c}$, where $\gamma_{c}$ and $\phi_{c}$ are, respectively, the safety factor for concrete (equal to 1.5 according to European practice) and the concrete strength reduction factor (equal to 0.75 according to American practice). The compressive strength of concrete has been replaced by its characteristic value $\left(f_{c k}\right.$, which can alternatively be taken as the specified concrete compressive strength $f_{c}{ }^{\prime}$ according to American practice).

The design steel contribution is

$$
V_{R, s, d}=\sum_{i=1}^{n} \sigma_{s i, d}(\psi) \cdot A_{s w i} \cdot \sin \left(\beta_{i}\right)
$$

where the stress in the steel can be obtained as

$$
\sigma_{s, d}=\min \left(\sigma_{s, e l, d} ; \sigma_{s, b, d} ; \sigma_{s, p, d} ; f_{y w, d}\right)
$$

where $f_{y w, d}$ is the design yield strength of the shear reinforcement (equal to $f_{y w} / \gamma_{s}$ according to European practice, where $\gamma_{s}$ is the safety factor of steel (1.15) or, according to American practice, $f_{y w d}=\phi_{s} f_{y w}$ where $\phi_{S}$ is the steel strength reduction factor [0.9]). The elastic activation can be calculated on the basis of Eq. (9) using design values ${ }^{20}$

$$
\sigma_{s, e l, d}=\sqrt{\frac{4 \cdot \tau_{b, d} \cdot E_{s} \cdot w_{b}}{d_{b}}}
$$

where $\tau_{b, d}$ is the design bond strength, whose value is ${ }^{10}$

$$
\tau_{b, d}=6.67 \cdot\left(\frac{f_{c k}}{20}\right)^{0.1} \mathrm{MPa} \quad\left(\tau_{b}=966 \cdot\left(\frac{f_{c}{ }^{\prime}}{2898}\right)^{0.1} \mathrm{psi}\right)
$$

For the pullout of anchorages, Eq. (11) should be modified to

$$
\sigma_{s i, p, d}=\frac{11}{\gamma_{c}} \cdot \sqrt{f_{c k}} \cdot \frac{\ell_{b i i}^{1.5}}{d_{b i}^{2}} \cdot\left(1+\frac{d_{i n f, i}}{\ell_{b i i}}\right)[\mathrm{N}, \mathrm{mm}]
$$

where for customary units (psi, in.), the coefficient $11 / \gamma_{c}$ has to be replaced by $27 \phi_{c}$.

\section{Punching outside shear-reinforced zone}

Punching outside the shear-reinforced zone is performed on the same basis of Eq. (12) but adopting design values

$$
V_{R, c, d}=\frac{2}{3 \cdot \gamma_{c}} \cdot \frac{b_{0, \text { out }} \cdot d_{v} \cdot \sqrt{f_{c k}}}{1+20 \cdot \frac{\psi \cdot d}{d_{g 0}+d_{g}}}[\mathrm{~N}, \mathrm{~mm}]
$$

for customary units (psi, in.), the coefficient $2 /\left(3 \gamma_{c}\right)$ has to be replaced by $8 \phi_{c}$.

\section{Crushing of concrete struts}

The same considerations as those of Eq. (13) apply, resulting in

$$
V_{R, \text { crush }}=\lambda \cdot \frac{2}{3 \cdot \gamma_{c}} \cdot \frac{b_{0, \text { in }} \cdot d \cdot \sqrt{f_{c k}}}{1+20 \cdot \frac{\psi \cdot d}{d_{g 0}+d_{g}}}
$$

where the proposed value $\lambda=2.6$ can be kept and, for customary units (psi, in.), the coefficient $2 /\left(3 \gamma_{c}\right)$ has to be replaced by $8 \phi_{c}$. 
$2 A_{s w}=$ cross-sectional area of a shear reinforcement

$3 E_{s}=$ modulus of elasticity of reinforcement

$4 \quad V=$ shear force

$5 \quad V_{\text {calc }}=$ calculated punching shear load

$6 \quad V_{\text {flex }}=$ shear force associated with flexural capacity of the slab

$7 \quad V_{R}=\quad$ punching shear strength

$8 V_{R, c}=\quad$ concrete contribution to punching shear strength

$9 V_{R, s}=$ shear reinforcement contribution to punching shear strength

$10 V_{R, c r u s h}=\quad$ punching shear strength (governing crushing of concrete struts)

$11 V_{R, i n}=$ punching shear strength (governing failure within shear-reinforced

12 zone)

$13 V_{R, \text { out }}=$ punching shear strength (governing failure outside the shear-reinforced

14 zone)

$15 V_{S L S}=$ shear force at time of strengthening

$16 V_{\text {test }}=$ measured punching shear load

$17 b_{0}=$ perimeter of the critical section

$18 b_{0, i n}=$ perimeter of the critical section (check of punching within the shear-

19 reinforced zone)

$20 b_{0, \text { out }}=$ perimeter of the critical section (check of punching shear outside the

21 shear-reinforced zone)

$22 d=$ effective depth (distance from extreme compression fibre to the centroid

23 of the longitudinal tensile reinforcement)

$24 d_{b}=$ diameter of a reinforcing bar

$25 d_{\text {inf }}=$ diameter of anchoring plate 
$1 d_{v}=$ reduced effective depth

$2 d_{g}=$ maximum diameter of the aggregate

$3 d_{g 0}=\quad$ reference aggregate size $(16 \mathrm{~mm}(0.63 \mathrm{in}))$

$4 f_{c}=$ average compressive strength of concrete (measured on cylinder)

$5 f_{y}=$ yield strength of flexural reinforcement

$6 f_{y w}=$ yield strength of shear reinforcement

$7 h=$ vertical distance between the tip of the crack and the point where the

8 shear reinforcement crosses the critical shear crack

$9 \quad \ell \quad=\quad$ span of a slab, length

$10 \ell_{b i i}=$ distance between the point where a shear reinforcement is crossed by

11 the critical shear crack and the lower end of the shear reinforcement

$12 \ell_{b s i}=$ distance between the point where a shear reinforcement is crossed by

13 the critical shear crack and the upper end of the shear reinforcement

$14 n_{a}=$ number of shear reinforcements per radius

$15 n_{r}=$ number of radii of shear reinforcement

16 $r_{s}=$ distance between the column of a slab and the line of contraflexure of

17 moments

$18 s_{0}=$ horizontal distance between the border of the support region and first

19 shear reinforcement

$20 s_{v}=$ horizontal distance between two adjacent reinforcements of same radius

$21 w_{b}=$ relative displacement of the lips of the critical shear crack parallel to

22 shear reinforcement

$23 \alpha=$ angle between the critical shear crack and the soffit of the slab

$24 \beta=$ angle between the shear reinforcement and the soffit of the slab

$25 \tau_{b}=$ bond strength 
$1 \rho=$ flexural reinforcement ratio

$2 \rho_{w}=$ shear reinforcement ratio

$3 \psi=$ rotation of slab outside the column region

$4 \psi_{\text {calc }}=$ calculated rotation at failure

$5 \psi_{R}=$ rotation of slab outside the column region at failure

$6 \psi_{S L S}=$ rotation of slab at time of strengthening

$7 \quad \psi_{\text {test }}=$ measured rotation at failure

$8 \quad \sigma_{s}=$ steel stress

$9 \sigma_{s, e l}=$ steel stress during elastic activation of shear reinforcement

$10 \sigma_{s, b}=$ maximum shear reinforcement stress due to bond failure

$11 \sigma_{s, p}=$ maximum shear reinforcement stress due to pull-out failure 12 
$2 V_{R d}=$ design punching shear strength

$3 V_{R, c, d}=\quad$ design concrete contribution to punching shear strength

$4 V_{R, s, d}=$ design shear reinforcement contribution to punching shear strength

$5 V_{R, c r u s h, d}=\quad$ design punching shear strength (governing crushing of concrete struts)

$6 V_{R, i n, d}=$ design punching shear strength (governing failure within shear-

7 reinforced zone)

$8 V_{R, \text { out }, d}=\quad$ design punching shear strength (governing failure outside the shear-

9 reinforced zone)

$10 f_{c k}=$ characteristic compressive strength of concrete (measured on cylinder)

$11 f_{c}^{\prime}=$ specified compressive strength of concrete (measured on cylinder)

$12 f_{y w d}=$ design yield strength of shear reinforcement

$13 \gamma_{c}=$ safety factor of concrete

$14 \gamma_{s}=$ safety factor of steel

$15 \phi_{c}=$ concrete strength reduction factor

$16 \phi_{s}=$ steel strength reduction factor

$17 \tau_{b, d}=$ design bond strength

$18 \sigma_{s d}=$ steel stress for design

$19 \sigma_{s, e l, d}=$ design steel stress during elastic activation of shear reinforcement

$20 \sigma_{s, b, d}=$ design maximum shear reinforcement stress due to bond failure

$21 \sigma_{s, p, d}=$ design maximum shear reinforcement stress due to pull-out failure 